Bull. Chem. Soc. Ethiop. 2019, 33(2), 285-292.

ISSN 1011-3924

(c) 2019 Chemical Society of Ethiopia and The Authors

Printed in Ethiopia

DOI: https://dx.doi.org/10.4314/bcse.v33i2.9

\title{
SYNTHESIS AND PHOTOCATALYTIC PROPERTIES OF A NEW PADDLE-WHEEL Cu(II) COMPLEX: AN INTEGRATED EXPERIMENTAL AND THEORETICAL INVESTIGATION
}

\author{
Bing Wang ${ }^{1,2}$, KeKe Liu ${ }^{3}$, Xiangyang Qin ${ }^{4 *}$, Bao-Hong Li $^{5^{*}}$, Qianyi Cheng ${ }^{5}$, Amita Singh $^{6}$ and \\ Abhinav Kumar ${ }^{6 *}$ \\ ${ }^{1}$ Out-patient Department of the Fourth Military Medical University, The 986th Hospital of the \\ Air Force, Xijing Hospital, Fourth Military Medical University, Xi'an, Shaanxi, 710032, China \\ ${ }^{2}$ School of Food and Biological Engineering, Shaanxi University of Science and \\ Technology, Xi'an 710021 \\ ${ }^{3}$ College of Pharmacy, Xi'an Medical University, Xi'an 710021, China \\ ${ }^{4}$ Department of Chemistry, School of Pharmacy, Fourth Military Medical University, Xi'an, \\ Shaanxi, 710032, China \\ ${ }^{5}$ Dongguan Key Laboratory of Drug Design and Formulation Technology, Key Laboratory of \\ Research and Development of New Medical Materials of Guangdong Medical University, \\ School of Pharmacy, Guangdong Medical University, Dongguan, 523808, China \\ ${ }^{6}$ Department of Chemistry, Faculty of Science, University of Lucknow, Lucknow, 226007, \\ India
}

(Received March 17, 2019; Revised April 20, 2019; Accepted July 2, 2019)

\begin{abstract}
A new paddle-wheel $\mathrm{Cu}(\mathrm{II})$ complex having formula $\left[\mathrm{Cu}(\mathrm{L})_{2}(\mathrm{DMF})\right]$ (1) (HL = 2-fluorobenzoic acid) has been synthesized and characterized using FTIR and single crystal X-ray diffraction. The single crystal Xray diffraction study indicates that the carboxylic acid ligand adopt bridging bidentate modes to coordinate $\mathrm{Cu}$ (II) centers thereby forming a binuclear copper(II)carboxylate type structure. The complex has been utilized as photocatalyst to photodegrade model aromatic dyes viz. methyl violet (MV) and rhodamine B (Rh B) in UV light. The photocatalytic results indicated that 1 offered moderate photocatalytic activity and offers good stability after performing photocatalysis. The plausible mechanism through which $\mathbf{1}$ exerted photcatalytic property had been proposed by using density of states (DOS) and partial DOS calculations.
\end{abstract}

KEY WORDS: Photocatalysis, Aromatic dyes, 2-Fluorobenzoic acid, Calculation

\section{INTRODUCTION}

The photocatalytic materials which are based on coordination complexes and metal-organic frameworks (MOFs) are gradually becoming a promising area of investigation as this class of materials offers good photocatalytic efficiency [1-2]. In such materials, varied interactions operating between inorganic/clusters and organic linkers led to variety of charge transfer transitions which is responsible for inducing better photocatalytic activities [3-4]. In view of these peculiar features associated with coordination complexes and MOFs, the photocatalytic performances of such materials have been explored extensively. For example, a 3D anionic framework was constructed using O-donor ligand, which exhibited good photocatalytic effects for degrading methyl orange (MO) [5]. Hou et al. have explored the polynuclear MOF based materials and tested them as photocatalyst for degradation of organic dyes [6]. These results indicated that the coordination complexes have high photocatalytic activities towards dye degradation due to different kinds of nuclei which form the cluster units [6]. Hence, in view of these pertinent findings the photocatalytic activities of MOF shaving varied type of frameworks should be explored further [7-8].

*Corresponding author. E-mail: qinxiangyang@fmmu.edu.cn; gdmcli@126.com

and abhinavmarshal@gmail.com

This work is licensed under the Creative Commons Attribution 4.0 International License 
As an important class of ligand, carboxylates can adopt diverse coordination modes, viz. monodentate, monodentate bridging, bidentate chelating and bidentate bridging and hence can lead to the formation of different two- and three-dimensional structures in the resulting complexes and MOFs. With these aspects in mind, we had made an attempt to explore the coordination properties of 2-fluorobenzoic acid [9] with copper(II) cation. In the present investigation, we report the synthesis and structure of a new $\mathrm{Cu}$ (II) based carboxylate complex having formula $\left[\mathrm{Cu}(\mathrm{L})_{2}(\mathrm{DMF})\right]$ (1) $(\mathrm{HL}=2$-fluorobenzoic acid). Further, the complex $\mathbf{1}$ had been used as photocatalytic materials for the degradation of aromatic dyes. The results of these investigations are presented herewith.

\section{EXPERIMENTAL}

\section{General considerations}

All reagents were commercially available and used without further purification. The powder Xray diffraction (PXRD) data for the complex was collected on Bruker Advance X-ray diffractometer equipped with $\mathrm{Cu}-\mathrm{K} \alpha$ radiation $(\lambda=1.5418 \AA)$ at $50 \mathrm{kV}, 20 \mathrm{~mA}$ with a scanning rate of $6^{\circ} / \mathrm{min}$ and a step size of $0.02^{\circ}$. FTIR spectrum for the complex as $\mathrm{KBr}$ pellet was recorded using Nicolet Impact 750 FTIR in the range of $4000-400 \mathrm{~cm}^{-1}$. The photocatalytic activity studies were carried out in a Shimadzu UV-Vis 2501PC spectrophotometer.

\section{$X$-ray crystallography}

The single crystal X-ray diffraction data was collected using Bruker SMART APEX diffractometer having graphite monochromated MoK $\alpha$ radiation $(\lambda=0.71073 \AA)$ by using $\omega$ scan technique. The intensities were corrected for absorption effects by using SADABS. The crystal structure of the complex was solved by direct method (SHLEXS-2014) and was refined using full-matrix least-squares procedures based on $F^{2}$ (SHELXL-2014) [10]. All the hydrogen atoms were generated geometrically and refined isotropically using a riding model. All nonhydrogen atoms were refined by applying anisotropic displacement parameters. CCDC number: 1898139.

\section{Synthesis of $\left[\mathrm{Cu}(\mathrm{L})_{2}(\mathrm{DMF})\right]$}

A mixture of $\mathrm{HL}(0.010 \mathrm{~g}), N, N$ '-dioxide-3,3'-benzocinnoline $(0.019 \mathrm{~g}), \mathrm{Cu}\left(\mathrm{NO}_{3}\right)_{2} \cdot 6 \mathrm{H}_{2} \mathrm{O}(0.036$ g) and $10 \mathrm{~mL}$ DMF in a $25 \mathrm{~mL}$ Teflon-lined stainless steel container was heated to $80{ }^{\circ} \mathrm{C}$ for 72 h. After that, container was cooled to room temperature with cooling rate of $5{ }^{\circ} \mathrm{C} / \mathrm{h}$ to obtain blue crystals of 1 in $58 \%$ yield which is based on $\mathrm{Cu}$. Calcd (\%) for $\mathrm{C}_{34} \mathrm{H}_{30} \mathrm{Cu}_{2} \mathrm{~F}_{4} \mathrm{~N}_{2} \mathrm{O}_{10}, \mathrm{C}$, 49.21; H, 3.64; N, 3.37. Found C, 49.01; H, 3.44; N, 3.19. IR ( $\left.\mathrm{cm}^{-1}\right): 2305$ (m); 1633 (vs); 1589 (m); 1467 (v); $1302(\mathrm{~m}) ; 1223(\mathrm{~m}) ; 890(\mathrm{~m}) ; 755(\mathrm{~m}) ; 659(\mathrm{~m})$.

\section{Photocatalytic method}

The photocatalytic reactions were performed as follows: The binuclear $\mathrm{Cu}$ (II) complex $\mathbf{1}$ (80 $\mathrm{mg}$ ) was dispersed in $50 \mathrm{~mL}$ aqueous solution containing methyl violet (MV)or rhodamine B $(\mathrm{Rh} \mathrm{B})(10 \mathrm{mg} / \mathrm{L})$. The mixture was stirred in dark for $30 \mathrm{~min}$ to ensure the establishment of adsorption-desorption equilibrium. The photocatalytic degradation of $\mathrm{MV} / \mathrm{Rh} \mathrm{B}$ was conducted on an XPA-7 type photochemical reactor equipped with a $100 \mathrm{~W}$ mercury lamp (mean wavelength $365 \mathrm{~nm}$ ) with light intensities at quartz tube positions of $12.7 \mathrm{~mW} / \mathrm{cm}^{2}$. During experiment, aliquots of $5.0 \mathrm{~mL}$ was taken out at specified time intervals and the clear solution was separated through centrifugation and then subsequently analyzed by using a UV-visible spectrophotometer. Additionally, control experiments were also conducted under similar reaction conditions in the absence of complex $\mathbf{1}$. 


\section{Computational details}

The probable mechanism dealing with the photocatalytic properties of $\mathbf{1}$ has been addressed using theoretical calculations. For this the gas phase geometry of the binuclear $\mathrm{Cu}$ (II) complex was fully optimized using the B3LYP functional [11-12] using $6-31 \mathrm{G}^{* *}$ basis set. All the calculations were performed using Gaussian 09 program [13]. After achieving global minimum the density of states (DOS) plot and partial DOS plots for the complex 1 was obtained using GaussSum 3.1 [14].

\section{RESULTS AND DISCUSSION}

\section{Synthesis and spectroscopy}

If the N,N'-dioxide-3,3'-benzocinnoline was absentin the reaction medium the desired complex was not obtained. Thus, the N,N'-dioxide-3,3'-benzocinnoline behave as template during the reaction between $\mathrm{HL}$ and $\mathrm{Cu}(\mathrm{II})$ salt. The IR spectra of $\mathbf{1}$ exhibits the main characteristic absorption bands in the range of $1462-1633 \mathrm{~cm}^{-1}$ which is mainly attributed to the asymmetric and symmetric stretching vibrations of the carboxylate groups. Also, the $\Delta v\left[v_{\mathrm{as}}(\mathrm{COO})-\right.$ $\left.v_{\mathrm{s}}(\mathrm{COO})\right]$ value of $150 \mathrm{~cm}^{-1}$ indicates the coordination of carboxylate groups to the central $\mathrm{Cu}(\mathrm{II})$ center.

\section{Crystal structure description}

The complex crystallizes in orthorhombic system with $P$ cab space group. The asymmetric unit in complex 1 possess $\mathrm{Cu}(\mathrm{II})$ cation, two 2-fluorobenzoates, and a DMF molecule. It contains the commonly occurring paddle-wheel unit $\mathrm{Cu}$ (II) dinuclear structure constructed by four bridging 2-fluorobenzoates and two DMF ligands (coordination through the DMF oxygen atom). The two halves of the dimeric species are related by an inversion centre at the mid-point of the $\mathrm{Cu}-\mathrm{Cu}$ bond. This arrangement means that the two DMF molecules are oriented in a linear fashion but pointing in opposite directions. Each $\mathrm{Cu}$ atom shows distorted octahedral coordination geometry with four carboxyl O-centers in the basal plane $[$ mean $\mathrm{Cu}-\mathrm{O}$ (carboxyl) $=1.951(3) \AA]$ and the Ocenters of the DMF ligands in the axial positions with a significantly longer $\mathrm{Cu}-\mathrm{O}$ distance [2.143(3) $\AA$ ]. All the $\mathrm{Cu}-\mathrm{O}$ bond distances in the basal plane are in agreement with the bond lengths found in similar complexes [15-16]. The $\mathrm{Cu} \cdots \mathrm{Cu}$ distance in dinuclear core is 2.630(5) $\AA$, and the $\mathrm{Cu}-\mathrm{Cu}$ distance between adjacent metal-complexes within each hydrogen-bonded chain is $9.6 \AA$. The shortest separation through space inter-chain distance between $\mathrm{Cu}(\mathrm{II})$ ions is $6.2 \AA$. The $\mathrm{Cu} \cdots \mathrm{Cu}$ separation in $\mathrm{Cu}_{2} \mathrm{X}_{4} \mathrm{~L}_{2}$ type systems is usually longer when the axial ligand is nitrogen instead of an oxygen atom. The $\mathrm{Cu} \cdots \mathrm{Cu}$ distances vary from $2.576-2.886 \AA$, for $\mathrm{CuO}_{4} \mathrm{~N}$ chromophores, and from 2.563-2.666 $\AA$ for $\mathrm{CuO}_{5}$ chromophores. Hence, the $\mathrm{Cu} \cdots \mathrm{Cu}$ distance in 1 agrees well the distances reported for $\mathrm{CuO}_{5}$ chromophores [17]. The carboxylate groups of 2-fluorobenoate have similar coordination, i.e. bridging bidentate to $\mathrm{Cu}(\mathrm{II})$. Additionally, the four adjoining binuclear units form a 1-D structure by intermolecular hydrogen-bonding with $d(\mathrm{C}-\mathrm{H} \bullet \bullet \mathrm{O})=2.66 \AA$ and $<(\mathrm{C}-\mathrm{H} \bullet \bullet \mathrm{O})=133^{\circ}$ (Figure $1 \mathrm{~b}$ ).

\section{Photocatalysis}

The complex 1 was used as photocatalyst to photo-decompose model organic dyes pollutants viz. methyl violet (MV) and rhodamine $\mathrm{B}(\mathrm{Rh} \mathrm{B})$. This had previously been established that in due course of degradation, MV and Rh B can be broken down into non-polluting compounds under light irradiation [18]. To monitor the photocatalytic degradation of $\mathrm{MV}$ and $\mathrm{Rh} \mathrm{B}$, the characteristic UV-Vis absorption band maxima of MV and Rh B observed at $\sim 550 \mathrm{~nm}$ were selected. As presented in Figure 2, the band intensity of both the dyes decreases with time when these dyeswere irradiated with UV in presence of 1 . The change in concentration of MV and Rh 
B solutions under UV irradiation had been plotted versus irradiation time. The results indicated that approximately $18 \%$ of MV and $13 \% \mathrm{Rh} \mathrm{B}$ decomposed during the starting $15 \mathrm{~min}$ of irradiation. The photocatalytic performance of the binuclear $\mathrm{Cu}(\mathrm{II})$ complex $\mathbf{1}$ had been compared to the highly connected framework $\left[\mathrm{Ag}_{7}\left(4,4^{\prime}-\mathrm{tmbpt}\right)(\mathrm{HL})_{2}(\mathrm{~L})\left(\mathrm{H}_{2} \mathrm{O}\right)\right]\left(4,4^{\prime}-\mathrm{tmbpt}=1\right.$ ((1H-1,2,4-triazol-1-yl)methyl)-3,5-bis(4-pyridyl)-1,2,4-triazole and $\mathrm{H}_{3} \mathrm{~L}=$ 5-(4-carboxybenzyloxy)-isophthalic acid) [19]. When 1 was employed as photocatalyst to decompose MV and $\mathrm{Rh} \mathrm{B}$, approximately $58 \%$ of MV and merely $23 \% \mathrm{Rh} \mathrm{B}$ was decomposed after $45 \mathrm{~min}$. For the sake of comparison, the total catalytic degradation efficiency of the control experiment (without any catalysts)only reached $11.7 \%$ and $13.6 \%$ after $45 \mathrm{~min}$, which indicated that small photo-degradation reaction going on between the $\mathbf{1}$ and dye solutions. The results indicate that $\mathbf{1}$ possess low capacity to induce photocatalytic decomposition of Rh B under UV irradiation. The observed variation in the photocatalytic activities can be ascribed to the nature of central metal centers, extent of the conjugation of organic ligands, the final framework structures of the complex and several other aspects [20-23]. When, $\left[\mathrm{Cu}_{2}(\mathrm{~L} 1) \cdot 5 \mathrm{DMF}\right]_{\mathrm{n}}\left(\mathrm{H}_{4} \mathrm{~L} 1=3,5-\mathrm{di}(3,5-\right.$ dicarboxyphenyl)nitrobenzene) has been used as photocatalyst for the photodegradation of $\mathrm{MV}$ and $\mathrm{Rh} \mathrm{B}$. The results indicated that approximately $70 \%$ of $\mathrm{MV}$ and $41 \%$ of $\mathrm{Rh} \mathrm{B}$ have been decomposed after 45 min irradiation [22]. A3D polymer based on $\left[\mathrm{Cu}_{2}(\mathrm{COO})_{4}\right]$ unit with the paddle wheel structure is a good photocatalyst for degradation of $\mathrm{Rh} \mathrm{B}$. The degradation efficiencies of $\mathrm{RhB}$ can increase to $90.3 \%$ after $165 \mathrm{~min}$ in the presence of catalyst [23]. It had been demonstrated that central $\mathrm{Cu}$ (II) center and the coordinated ligands may get involved in the photocatalytic degradation of aromatic dyes [21].
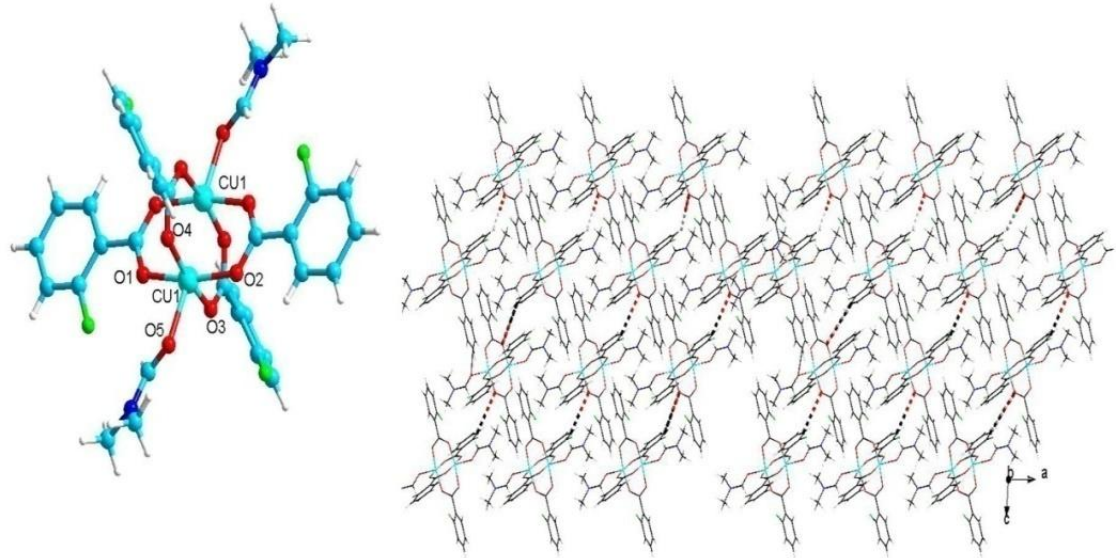

Figure 1. (a) Perspective view of coordination geometries around $\mathrm{Cu}$ (II) center; (b) 1-D chains connected by hydrogen bonds (dash line represented the H-bonded interactions).

The powder X-ray diffractogram (PXRD) for 1 was recorded after performing photocatalytic experiments. The obtained diffractogram indicated resemblance of diffraction pattern with that of simulated and as-synthesized $\mathbf{1}$. This indicates that $\mathbf{1}$ maintains its crystalline nature after photocatalysis which further proves stability and reusability (Figure 3a). As confirmed by PXRD and SEM, the structure integrity and surface morphology of $\mathbf{1}$ are well preserved which indicates its potential as a robust photocatalyst for photodegrading the organic dyes in wastewater (Figure 3b-3c).

To establish the plausible photocatalytic mechanism through which the photo-degradation of the aromatic dyes have been executed by $\mathbf{1}$, band structure calculations of the binuclear $\mathrm{Cu}$ (II) complex which is based on density functional theory (DFT) method has been performed. The band structure which is precisely represented in terms of density of states (DOS) and partial 
DOS plots have been presented in Figure 4. The DOS and partial DOS plots for the complex indicates that the valence band present just below the Fermi level is having contributions from aromatic carbonsand the carboxylate oxygens of the L ligand with small contribution from the $\mathrm{Cu}$ (II) center. Also, the conduction band in the case of $\mathbf{1}$, lying just above the Fermi level in the range of -1.2 to $-0.5 \mathrm{eV}$ have been derived from aromatic carbons with small contributions from oxygen and metal centers. Hence, in 1, the electronic transitions are mainly operating from aromatic center to another aromatic region (ligand-to-ligand) some mixing from $\mathrm{Cu}(\mathrm{II})$ and carboxylate oxygen centers.
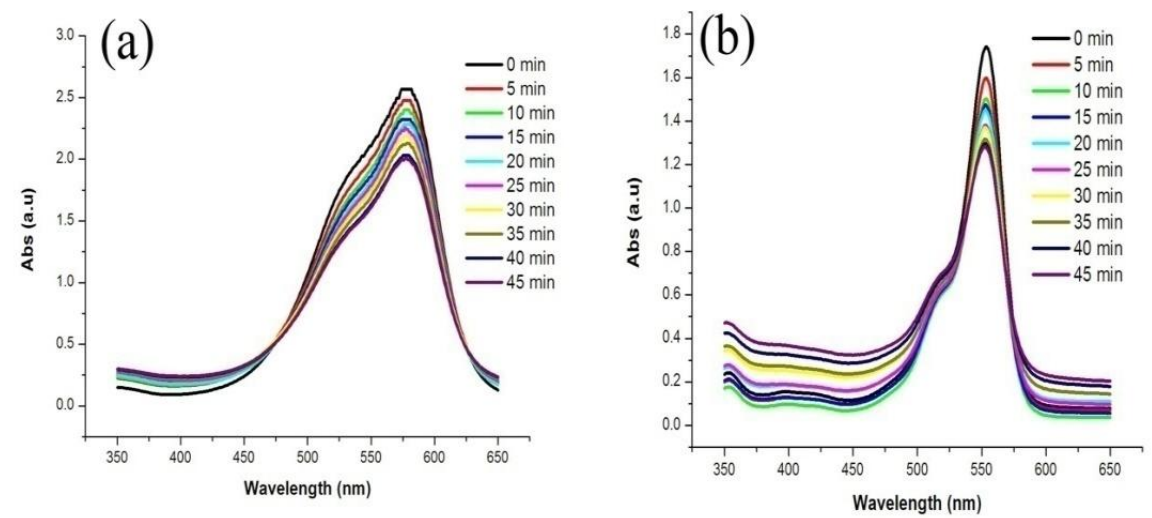

Figure 2. (a) Absorption spectra of the MV solution during the decomposition reaction under the light irradiation with the presence of complex 1; (b) (a) Absorption spectra of the Rh B solution during the decomposition reaction under the light irradiation with the presence of complex 1.

(a)

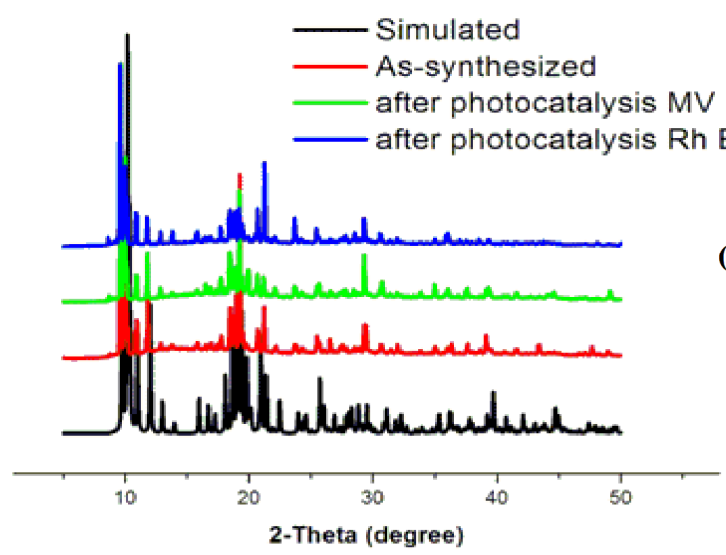

(b)

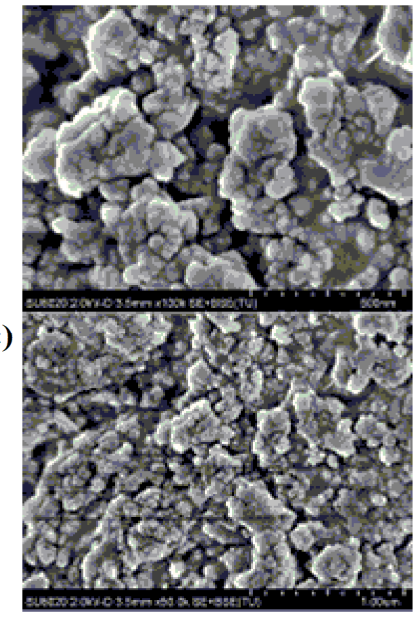

Figure 3. (a) The simulated and experimental PXRD patterns of 1 before and after performing photocatalytic experiments; (b) SEM image of 1 before photocatalysis; (c) SEM image of 1 after photocatalysis. 


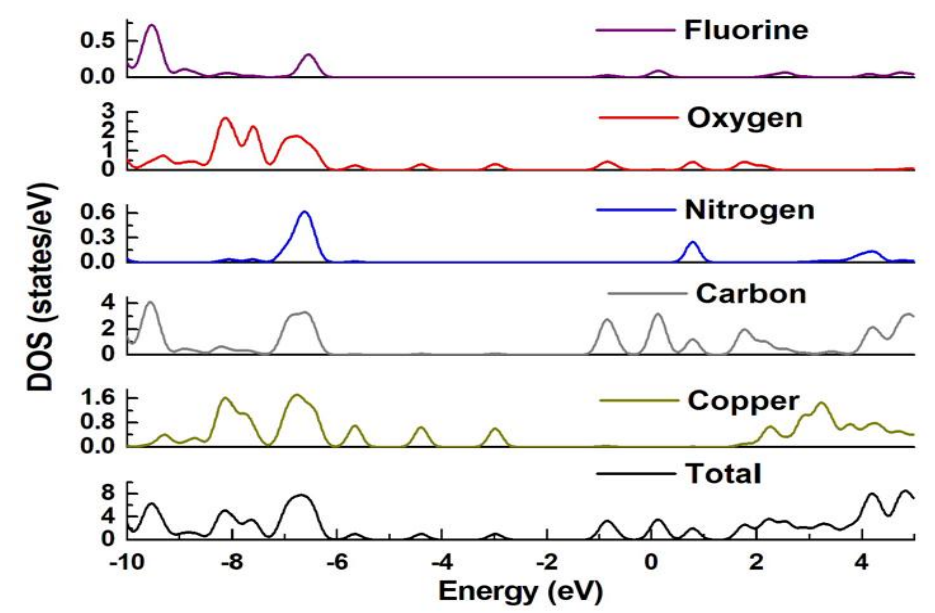

Figure 4. The density of states as well as partial density of states plots for the binuclear $\mathrm{Cu}$ (II) complex 1 .

During photoexcitation of $\mathbf{1}$, charge transfer transitions from $\mathrm{HOMO} \rightarrow$ LUMO takes place. After charge transfer, the electron deficient HOMO requires an electron to revert back to its stable state. Hence, an electron is captured from water molecule, which gets oxygenated into $\cdot \mathrm{OH}$ active species. These $\mathrm{OH}$ radicals decomposes the dye effectively to complete the photocatalytic process. The mechanistic scheme suggested to operate during the photocatalytic decomposition of dyes with the aid of binuclear complex 1 can be summarised as follows [24]:

$$
\begin{aligned}
& 1 \stackrel{h v}{\rightarrow} 1^{*} \text { i.e. } 1\left(\mathrm{~h}^{+}+\mathrm{e}^{-}\right) \\
& 1\left(\mathrm{~h}^{+}+\mathrm{e}^{-}\right)+\mathrm{H}_{2} \mathrm{O} \stackrel{h v}{\rightarrow} 1\left(\mathrm{e}^{-}\right)+\mathrm{HO}+\mathrm{H}^{+} \\
& \mathrm{HO}+\mathrm{MV} \stackrel{h v}{\rightarrow} \text { oxidation products } \rightarrow \mathrm{CO}_{2}+\mathrm{H}_{2} \mathrm{O} \\
& 1\left(\mathrm{e}^{-}\right)+\mathrm{O}_{2} \stackrel{h v}{\rightarrow} 1\left(\mathrm{O}_{2}^{-}\right) \\
& \mathrm{O}_{2}^{-} / \mathrm{HO}_{2}{ }^{-}+\mathrm{S} \stackrel{h v}{\rightarrow} \text { oxidation products }
\end{aligned}
$$

The complex 1 gets photo-excited to produce electron-hole pair (equation 1). This photo-excited molecule undergo reaction with $\mathrm{H}_{2} \mathrm{O}$ (i.e. oxidative hole trapping) to produce hydroxyl $\left(\mathrm{OH}^{\prime}\right)$ radical (equation 2). The hydroxyl radical reacts subsequently with aromatic dyes in variety of ways to produce oxidized products [23]. The dioxygen molecule $\left(\mathrm{O}_{2}\right)$ behave as very effective oxidant for the reduced $\mathbf{1}\left(\mathrm{e}^{-}\right)$and its main action is to regenerate the reduced photocatalyst $\mathbf{1}$. The formation of superoxide radical anion $\mathrm{O}_{2}{ }^{-}\left(\mathrm{O}_{2}{ }^{-}+\mathrm{H}^{+} \leftrightarrow \mathrm{HO}_{2}{ }^{\prime}\right)$ may participate further in oxidative process [25-26].

\section{CONCLUSION}

In summary, s a new copper(II) complex with paddle-wheel unit has been presented. The complex behaved like a photocatalyst to photo-degrade organic dyes of MV and Rh B. However, the photocatalytic results were modest, but using precise carboxylate ligands having pre-tuned electronic functions can develop suitable $\mathrm{Cu}(\mathrm{II})$ based complexes, which can offer better catalytic properties. 


\section{ACKNOWLEDGEMENTS}

The authors acknowledge financial assistance from Shaanxi natural science basic research program (2017JZ023) and Special Funds for Science and Technological Innovation of undergraduates in Guangdong Province (pdjha2019b0221, pdjha2019b0222, pdjha2019b0219, pdjha2019b0215).

\section{REFERENCES}

1. Mu, B.; Li, C.X.; Song, M.; Ren, Y.L.; Huang, R.D. The electrochemical properties, nitrogen adsorption, and photocatalytic activities of three 3D metal-organic frameworks bearing the rigid terphenyl tetracarboxylates ligands. CrystEngComm 2016, 18, 3086-3094.

2. Getman, R.B.; Bae, Y.S.; Wilmer, C.E.; Snurr, R.Q. Review and analysis of molecular simulations of methane, hydrogen, and acetylene storage in metal-organic frameworks. Chem. Rev. 2012, 112, 703-723.

3. Ma, A.Q; Wu, J.; Han, Y.T.; Chen, F.M.; Li, B.H.; Cai, S.; Huang, H.; Singh, A.; Kumar, A.; Liu, J.Q. Rational synthesis of a luminescent uncommon $(3,4,6)$-c connected Zn(II) MOF: A dual channel sensor for the detection of nitroaromatics and ferric ions. Dalton Trans. 2018, 47, 9627-9633.

4. Wu, X.R.; Shen, X.; Fan, S.R.; Trivedi, M.; Li, B.H.; Kumar, A.; Liu, J.Q. The utilization of a stable 2D bilayer MOF for simultaneous study of luminescent and photocatalytic properties: Experimental studies and theoretical analysis. RSC Adv. 2018, 8, 23529-23538.

5. Li, M.; Zhao, S.; Peng, Y.F.; Li, B.L.; Li, H.Y. A polythreading array formed by a $(3,5)-$ connected 3D anionic network and 1D cationic chains: Synthesis, structure, and catalytic properties. Dalton Trans. 2013, 42, 9771-9776.

6. Liu, L.; Ding, J.; Huang, C.; Li, M.; Hou, H.W.; Fan, Y.T.; Polynuclear Cd(II) polymers: Crystal structures, topologies, and the photodegradation for organic dye contaminants. Cryst. Growth Des. 2014, 14, 3035-3043.

7. Trivedi, M.; Nagarajan, R.; Kumar, A.; Kociok-Köhn, G.; Sudlow, A.L. A combined experimental and computational investigation on Tetrakis- $\mu$-acetato-bis(acetamido)dicopper(II) and its application as a single source precursor for copper oxide. Inorg. Chem. Comm. 2011, 14, 920-924.

8. Ma, L.F.; Han, M.L.; Qin, J.H.; Wang, L.Y.; Du, M. Mn ${ }^{\mathrm{II}}$ coordination polymers based on bi-, tri-, and tetranuclear and polymeric chain building units: Crystal structures and magnetic properties. Inorg. Chem. 2012, 51, 9431-9442.

9. Zheng, M.; Zheng Y.Q.; Zhang, B.S. Synthesis, crystal structures, and characterization of copper(II) carboxylate complexes incorporating 1,10-phenanthroline and bipyridine. $J$. Coord. Chem. 2011, 64, 3419-3431.

10. Sheldrick, G.M. Crystal structure refinement with SHELXL. Acta. Crystallogr. Sect. A: Found. Adv. 2015, 7, 3-8.

11. Becke, A.D. Density-functional thermochemistry. III. The role of exact exchange. J. Chem. Phys 1993, 98, 5648-5652.

12. Lee, C.T.; Yang, W.T.; Parr, R.G. Development of the Colle-Salvetti correlation-energy formula into a functional of the electron density. Phys. Rev. B Condens. Matter Mater. Phys. 1998, 37, 785-789.

13. Frisch, M.J.; Trucks, G.W.; Schlegel, H.B.; Scuseria, G.E.; Robb, M.A.; Cheeseman, J.R.; Montgomery, J.A.; Vreven Jr., T.; Kudin, K.N.; Burant, J.C. Millam, J.M.; Iyengar, S.S.; Tomasi, J.; Barone, V.; Mennucci, B.; Cossi, M.; Scalmani, G.; Rega, N.; Petersson, G.A.; Nakatsuji, H.; Hada, M.; Ehara, M.; Toyota, K.; Fukuda, R.; Hasegawa, J.; Ishida, M.; Nakajima, T.; Honda, Y.; Kitao, O.; Nakai, H.; Klene, M.; Li, X.; Knox, J.E.; Hratchian, H.P.; Cross, J.B.; Bakken, V.; Adamo, C.; Jaramillo, J.; Gomperts, R.; Stratmann, R.E.; Yazyev, O.; Austin, A.J.; Cammi, R.; Pomelli, C.; Ochterski, J.W.; Ayala, P.Y.; Morokuma, 
K.; Voth, G.A.; Salvador, P.; Dannenberg, J.J.; Zakrzewski, V.G.; Dapprich, S.; Daniels, A.D.; Strain, M.C.; Farkas, O.; Malick, D.K.; Rabuck, A.D.; Raghavachari, K.; Foresman, J.B.; Ortiz, J.V.; Cui, Q.; Baboul, A.G.; Clifford, S.; Cioslowski, J.; Stefanov, B.B.; Liu, G.; Liashenko, A.; Piskorz, P.; Komaromi, I.; Martin, R.L.; Fox, D.J.; Keith, T.; Al-Laham, M.A.; Peng, C.Y.; Nanayakkara, A.; Challacombe, M.; Gill, P.M.W.; Johnson, B.; Chen, W.; Wong, W.M.; Gonzalez, C.; Pople, J.A. Gaussian 09 revision B.01, Gaussian, Inc.: Wallingford CT; 2009.

14. O'Boyle, N.M.; Tenderholt, A.L.; Langner, K.M. Cclib: A library for package-independent computational chemistry algorithms. J. Comp. Chem. 2008, 29, 839-845.

15. Shahid, M.; Mazhar, M.; Helliwell, M.; Akhtar, J.; Ahmad, K. Catena-poly[[tetrakis( $\mu_{2}-$ acetato- $\left.\kappa^{2} \mathrm{O}: \mathrm{O}^{\prime}\right)$ dicopper(II) $\left.(\mathrm{Cu}-\mathrm{Cu})\right]-\mu_{2}$-acetato- $\kappa^{2} \mathrm{O}: \mathrm{O}^{\prime}-\left[\mathrm{bis}\left[\mu_{2}-3\right.\right.$ (dimethylamino)propan-1-

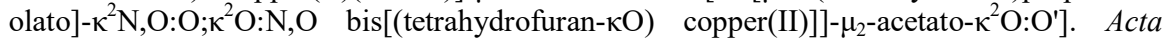
Cryst. 2008, 64, 1139-1140.

16. Aakeröy, C.B. Scott, B.M.T. Smith, M.M. Urbina, J.F. Desper, J. Establishing amide ‥ amide reliability and synthon transferability in the supramolecularassembly of metal-containing one-dimensional architectures. Inorg. Chem. 2009, 48, 4052-4061.

17. Melník, M.; Smolander, K.; Sharrock, P. Spectroscopic, magnetic and structural characterization of tetrakis- $\mu$-acetato-bis(3-pyridylcarbinol)dicopper(II) monomethylene chloride. Inorg. Chim. Acta 1985, 103, 187-194.

18 Addison, A.W. Rao, T.N. Reedijk, J. Rijn. J. Verschoor, C. Synthesis, structure, and spectroscopic properties of copper(II) compounds containing nitrogen-sulphur donor ligands: The crystal and molecular structure of aqua[1,7-bis(N-methylbenzimidazol-2'-yl)2,6-dithiaheptane]copper(II) perchlorate. J. Chem. Soc., Dalton Trans. 1984, 10, 1349-1356.

19. Cheng, Y.J.; Wang, R.; Wang, S.; Xi, X.J.; Ma, L.F.; Zang, S.Q. Encapsulating $\left[\mathrm{Mo}_{3} \mathrm{~S}_{13}\right]^{2-}$ clusters in cationic covalent organic frameworks: Enhancing stability and recyclability by converting a homogeneous photocatalyst to a heterogeneous photocatalyst. Chem. Commun. 2018, 54, 13563-13566.

20. Liu, B.; Yu, Z.T.; Yang, J.; Wu, H.; Liu, Y.Y.; Ma, J.F. First three-dimensional inorganicorganic hybrid material constructed from an "inverted Keggin" polyoxometalate and a copper (I)-organic complex. Inorg. Chem. 2011, 50, 8967-8972.

21 Zhao, Y.; Deng, D.S.; Ma, L.F.; Ji, B.M.; Wang, L.Y. A new copper-based metal-organic framework as a promising heterogeneous catalyst for chemo-and regio-selective enamination of $\beta$-ketoesters. Chem. Commun. 2013, 49, 10299-10301.

22. Pan, Y.; Liu, W.C.; Liu, D.; Ding, Q. J.; Liu, J. Q.; Xu, H. J.; Trivedi, M.; Kumar, A.; A 3D metal-organic framework with isophthalic acid linker forphotocatalytic properties, Inorg. Chem. Commum. 2019, 100, 92-96.

23. Qian, L.L.; Han, S.S.; Zheng, L.Y.; Yang, Z.; Li, K.; Li, B.L.; Wu, B. Syntheses, structures and properties of structural diversity of 3Dcoordination polymers based on bis(imidazole) and dicarboxylate. Polyhedron 2019, 162, 303-310.

24. Guo, J.; Yang, J.; Liu Y.Y.; Ma, J.F. Two novel 3D metal-organic frameworks based on two tetrahedral ligands: Syntheses, structures, photoluminescence and photocatalytic properties. CrystEngComm 2012, 14, 6609-6617.

25. Wu, W.P.; Liu, W.C.; Qiu, S.W.; Ma, A.Q.; Dai, W.; Qian, Y.; Kumar, A. Application of a water stable $\mathrm{Zn}$ (II) glutamate metal organic framework for photocatalytic degradation of organic dyes. Bull. Chem. Soc. Ethiop. 2019, 33, 43-50.

26. Welderfael, T.; Yadav, O.P.; Taddesse, A.M.; Kaushal, J. Synthesis, characterization of Ag$\mathrm{N}$ codoped $\mathrm{ZnO}$ nanoparticles for degradation of methyl red. Bull. Chem. Soc. Ethiop. 2013, $27,221-232$. 